\title{
A UTILIZAÇÃO DA TABLATURA COMO FORMA DE LEITURA MUSICAL
}

\author{
Alexsander VANZELA ${ }^{1}$ \\ Ana Paula Conte VANZELA ${ }^{2}$ \\ ${ }^{1}$ Conservatório Estadual de Música "Lobo de Mesquita". Graduado em Gestão do Comércio em 2002, Licenciado em \\ Música com Habilitação em Guitarra pela UninCor em 2011 com Pós Graduação em Educação Musical pela UCAM - \\ Prominas em 2012. alexvanzela@gmail.com,www.alexvanzela.com \\ ${ }^{2}$ UFVJM - Universidade Federal dos Vales do Jequitinhonha e Mucuri. apvanzela@ gmail.com
}

\section{Recebido em: 09/05/2014 - Aprovado em: 30/06/2014 - Disponibilizado em: 30/07/2014}

RESUMO: Por muitos séculos a tablatura vem sendo utilizada para a escrita e consequentemente leitura de alguns instrumentos musicais de cordas. Talvez o instrumento mais antigo seja a Vihuela e depois o Alaúde, precedido pela guitarra acústica comumente chamada no Brasil de violão, que mais tarde com a modernização e também para obter um som mais alto apareceu à guitarra elétrica. Com mo passar do tempo houve a necessidade de uma estruturação para a melhoria do ensino, escrita e leitura da guitarra elétrica. Para a melhor compreensão dos alunos de guitarra elétrica foi utilizada para esses fins a partitura e a tablatura. Hoje em dia com o avanço da tecnologia utilizada para o ensino, a tablatura aliada a partitura para o ensino da guitarra elétrica vem de encontro à necessidade de um facilitador de leitura e consequentemente maior rapidez para utilizar não somente as técnicas apuradas, mas a associação da tablatura com a partitura faz com que o músico possa saber perfeitamente o que fazer e qual técnica utilizar em determinado momento. Juntamente com a partitura o performer entende qual é o andamento, o tempo e as demais características da música que está escrito na pauta. Neste trabalho estarei focando a leitura para a guitarra elétrica na qual irei chamar apenas de "guitarra".

Palavras chave: Tablatura, Guitar Pro 6, Técnicas de Guitarra, Leitura, Partitura.

ABSTRACT: For many centuries the tab is being used for writing and consequently reading some stringed musical instruments . Perhaps the oldest instrument is the Vihuela and then the Lute, preceded by acoustic guitar commonly called in Brazil guitar, later with modernization and also to get a louder sound appeared to electric guitar. With mo over time there was a need for a structure to improve teaching, writing and reading of the electric guitar . For a better understanding of students electric guitar was used for those purposes the sheet music and tablature. Nowadays with the advancement of technology used for education, coupled with the sheet music tablature for teaching electric guitar comes against the need for a facilitator of reading and therefore faster to use not only the accurate techniques , but the association of tablature to sheet music makes the musician can know exactly what to do and which technique to use at any given time. Along with the score the performer understands what the progress, time and other characteristics of the music that is written on the staff. This work will be focusing on reading for electric guitar in which I will only call " guitar ".

Keywords: TAB, Guitar Pro 6, Guitar Techniques, Reading, Partitura.

\section{MATERIAL E MÉTODO}

Para as figuras de partituras, tablaturas e do braço da guitarra utilizarei o programa Guitar Pro 6 por ser muito didático, utiliza a tablatura para escrever e a partitura vem como forma de complementação, mostrando o tempo e todas as características das notações musicais.

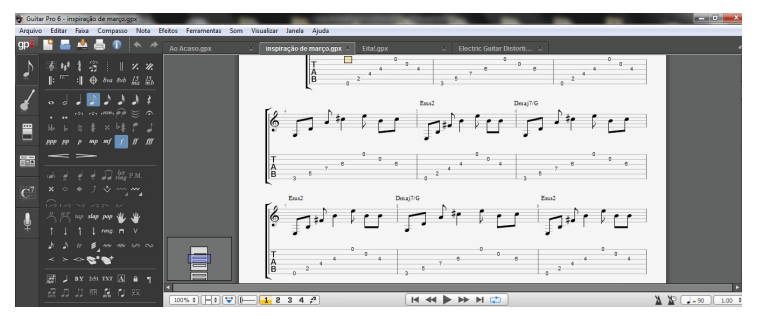

\section{INTRODUÇÃO}

A guitarra teve seu início notório nos Estados Unidos com os luthiers Leo Fender e Les Paul, onde se originaram os modelos mais clássicos de guitarra. Leo Fender surgiu com os modelos Telecaster e Stratocaster, guitarras com captadores single ou humbukers, corpo maciço e um timbre marcante. Já Les Paul fez os modelos Les Paul com captadores P-90 que visualmente se parecem com humbucker, mas que na verdade são single e também a SG com captadores humbuking. Existem mais modelos inventados pelos dois luthiers, o fato é que: 
"esses modelos são referências principais em termo de sonoridade, gênero e atitude dentro do rock" 1

Mostrei aqui duas referências de luthiers para uma pequena introdução no mundo das guitarras, onde o tema da escrita é uma questão muito interessante, principalmente quando tratamos das técnicas de guitarra e no que se refere à sua notação musical.

O referido artigo irá tratar apenas da escrita musical para o aperfeiçoamento do aluno de guitarra, utilizando programas de escrita e leitura.

É comum o questionamento por parte de professores de violão clássico e outros instrumentos a respeito da utilização da Tablatura para o ensino de guitarra, visando entender como a tablatura contribui para a leitura e consequentemente para a performance do músico leitor.

O pensamento geral no ensino de música clássica entende que em se tratando de educação musical deveria ser utilizada somente a partitura uma vez que a tablatura viria atrapalhar o aprendizado da leitura na pauta ao aprisionar o aluno à execução mecânica das notas. Entretanto no aprendizado de guitarra, a tablatura é essencial e complementa o uso da partitura, não possuindo o intuito de substituí-la, mas de melhor definir a utilização da localidade das notas na ampla escala da guitarra. Assim, é imprescindível para a formação musical do guitarrista.

Como a leitura de guitarra é um pouco mais complexa que a do violão, pela sua rapidez, utilizando semicolcheias, fusas e até semifusas e como a utilização de algumas técnicas não existentes no instrumento acústico (violão) não é comum, alguns professores de violão erudito não associam a qualidade de ensino a uma melhor performance somente na questão partitura sem que o aluno apenas leia a pauta, para eles o importante é apenas a leitura de partitura e não a aliança, ou melhor a utilização da tablatura como uma escrita e ou ainda, a leitura da tablatura juntamente com a partitura.

${ }^{1}$ HORA, Victor Medeiros. A Importância da Guitarra Elétrica no Rock para a Educação Musical a partir

de sua Consolidação Acadêmica e Exposição na Mídia.
Quero aqui não comparar instrumentos e muito menos professores, apenas salientar que pela consequência da guitarra ser um instrumento mais atual e rápido, possui requintes timbrísticos que o violão não tem daí surge à importância da utilização da tablatura para o auxílio da partitura.

Para se entender um pouco o porquê da tablatura, vou mostrar a extensão musical de uma guitarra, normalmente a guitarra possui $21,22,24$ casas e existem guitarras com 27 ou mais casas, apenas as 12 casas, ou seja, apenas uma oitava do braço, visto que nas guitarras que possuem 24 trastes existem duas oitavas.

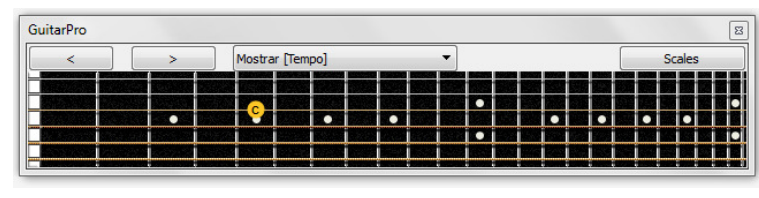

Para um exemplo prático, vamos imaginar uma nota: Mi como mostra a pauta abaixo:

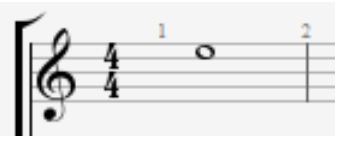

Quando olhamos para essa nota (mi), sabemos que ela é utilizada na $1^{\mathrm{a}}$ corda solta, por ser mais fácil a visualização no braço do instrumento, mas é ai que começa a complicação, pois tanto no violão quanto na guitarra existem vários mi’s e dependendo da notação é muito difícil achar onde é exatamente que o autor quer que toque, visto que esta nota pode ser encontrada nas seis cordas e em diferentes locais do braço.

$\mathrm{O}$ primeiro mi encontra-se na primeira corda solta; o segundo na segunda corda, $5^{\mathrm{a}}$ casa; o terceiro mi encontra-se na terceira corda, $9^{\mathrm{a}}$ casa; o quarto mi encontra-se na quarta corda, $14^{\mathrm{a}}$ casa; o quinto mi encontra-se na quinta corda, $19^{\mathrm{a}}$ casa e por fim o sexto mio encontra-se na sexta corda, $24^{\mathrm{a}}$ casa, como é mostrado na figura abaixo:

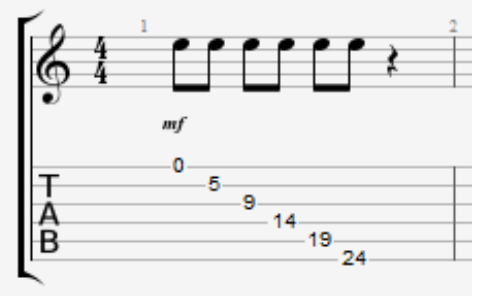


Então vejamos com a tablatura a visualização de onde a nota deverá ser executada, há aqui um facilitador para a leitura do músico, ou seja, para o músico que está lendo e posteriormente executando qualquer melodia, solo, enfim, uma música o torna de certo ponto agradável para a execução, sem perda de tempo para descobrir onde é o local correto.

Vejamos abaixo um trecho de uma guitarra base e um lick de guitarra:

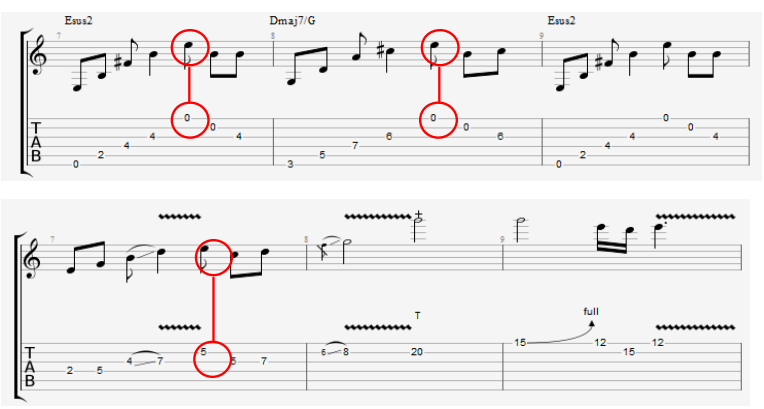

A guitarra base está fazendo um acorde de Esus2 e depois Dmaj7/G e o "mi” está sendo executado nos dois acordes, se não houvesse a tablatura os acordes poderiam ser montados de maneira que não apareceria o "mi aberto", ou seja, com a corda solta.

Já na guitarra solo o mi acontece na quinta casa da segunda corda e podemos notar que a notação desta tablatura existe algumas informações que nem sempre a partitura consegue informar, vamos ver cada técnica.

No compasso 7 as técnicas iniciam com um slide, ou seja, um glissando de si ( $4^{\mathrm{a}}$ casa, terceira corda) para o ré ( $7^{a}$ casa, terceira corda), precedido por um vibrato feito com a mão esquerda, ou a mão da escala.

No compasso 8 há novamente um slide de fá (6 $6^{\mathrm{a}}$ casa, segunda corda) para sol ( $8^{\mathrm{a}}$ casa, segunda corda), precedido por um vibrato da mão da escala e posteriormente um Tapping em sol $\left(20^{\mathrm{a}}\right.$ casa, segunda corda) uma oitava acima.

No compasso 9 há um Bend, que na partitura não possui essa notação, iniciando em sol (15 casa, primeira corda) e subindo um tom, pois na tablatura existe a expressão "full" que quer dizer "subir um tom”. Então a nota inicial em sol e chega até lá sem a precisão de mudanças de casas, pois esta técnica faz com que o guitarrista consiga de $1 / 4$ de tom acima até 2 ou 2,5 tons acima.

Em outro trecho existe a presença do mi tocado em outra região da guitarra, vejamos:

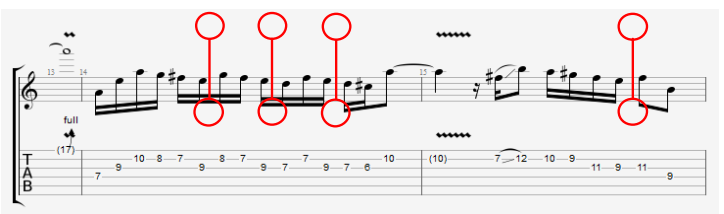

Por coincidência todas as notas foram tocadas no mesmo local na $3^{\mathrm{a}}$ corda.

Quando tento esclarecer a possibilidade de que a tablatura ajuda a leitura, vemos no trecho que a guitarra solo faz um Bend o mesmo não aparece na pauta, porque não existe essa técnica para se escrever, sendo assim a tablatura vem em socorro para a escrita e posteriormente a sua leitura.

\section{TÉCNICAS DE GUITARRA}

As diferentes técnicas que são utilizadas na guitarra possuem por sua vez os nomes em inglês, por que o seu início se deu nos Estados Unidos. Aqui reescrevo um trecho de Henderson:

"Estudioso sério da música clássica européia, como também do blues e do $R \& B$, Cox reconheceu, ao ouvir Jimmy tocar, um gênio que se situava entre Beethoven e John Lee Hooker." (HENDERSON, p.56, 1993).

Mostrei este trecho para ilustrar que a guitarra possui influência clássica, onde por exemplo Yngwie Malmsteen toca Beethoven Pagannini e Bach, suas obras são baseadas no período barroco e é um guitarrista viurtuose que tem em suas técnicas muitos arpejos, alavancadas e muita velocidade como seus pontos fortes. Também é o caso de vários guitarristas atuais como Steve Vai, Joe Satriani, Eddie Van Halem, Staley Jordan, entre tantos outros.

As técnicas utilizadas inicialmente são feitas baseadas nas músicas primitivas, ou seja, as primeiras músicas onde o músico se esforçava para tocar com maestria e precisão determinada nota e assim fazer acontecer o que o escritor musical estava pensando em realizar. 


\section{Técnicas relacionadas à partitura e tablatura}

1- Ligados ascendentes e descendentes

Estes ligados recebem o nome de pull off $(\mathrm{P}) \mathrm{e}$ hammer on $(\mathrm{H})$, muito utilizados em guitarra.

Vejamos aqui que os dois modelos aparecem tanto na pauta quanto na tablatura, mas na leitura da tablatura entende-se muito bem onde é o local para tocar, ou seja o dó na $5^{\mathrm{a}}$ casa, terceira corda e o ré na $7^{\mathrm{a}}$ casa, terceira corda.

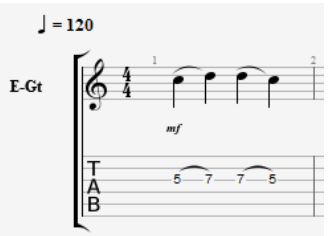

2- Glissando ou Slide, técnica utilizada para mudança de nota na mesma corda apenas deslizando o dedo.

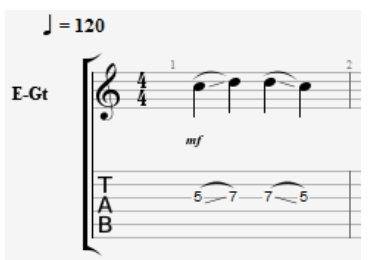

3- Harmônico Natural é uma técnica onde possibilita a frequência de algumas notas, utilizando os dedos da mão da escala para somente tocar de leve as cordas ou a corda em determinada casa. Normalmente os harmônicos naturais aparecem nas casas 5, 7 e 12, mas em outras casas também é possível conseguir. Notamos que na tablatura é fácil a compreensão de onde deve-se tocar para obter o som desejado, mas na pauta o que temos é apenas o resultado da técnica não sabendo onde ela é iniciada.

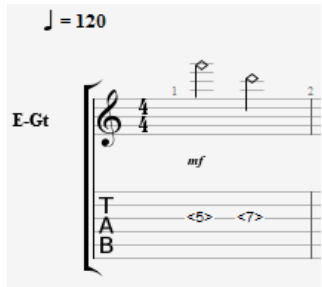

4- Harmônico Artificial é feito utilizando a mão da palheta para tocar a corda. Pode-se achar este harmônico palhetando em cima dos captadores do braço e meio. Em alguns casos há a possibilidade de fazer esses harmônicos utilizando a mão da palheta com um tapping na escala obtendo assim o som desejado. Veja neste caso que na pauta aparecem duas notas para cada nota ficando meio confuso, mas na tablatura aparece apenas uma mas com o dizer A.H. significando o Harmônico Artificial com a facilidade de saber onde deve ser tocada a nota.

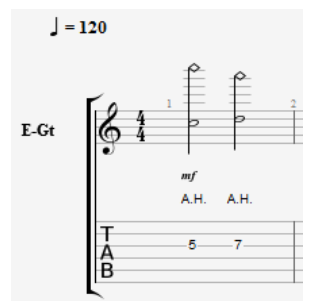

5- Vibrato é uma técnica muito utilizada pelos guitarristas, faz ênfase no final de uma frase ou pode dar a intenção de intensidade do som. Neste caso a pauta aparece semelhante à tablatura, podendo o leitor entender rapidamente qual técnica utilizar. Muitos guitarristas novatos confundem este sinal de vibrato com a mão da escala com o vibrato com alavanca que é feito de outra forma.

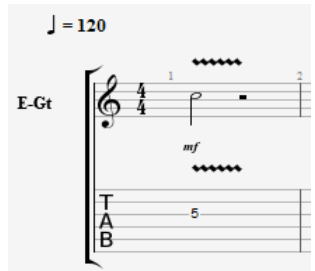

6- Vibrato com alavanca é uma técnica utilizada apenas pelas guitarras elétricas que possuem alavanca. Visa intensificar o som de maneira que o efeito seja subindo e descendo tons utilizando a alavanca, que é uma peça que fica na ponte móvel. 


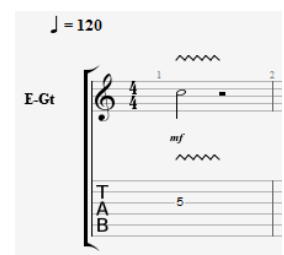

7- Trêmulo com alavanca pode ser efetuado subindo ou descendo tons. Neste exemplo o guitarrista deverá descer um tom e retornar.

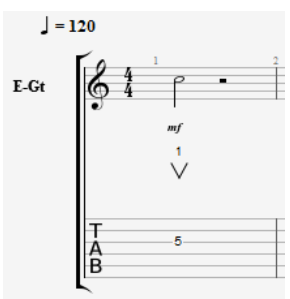

8- Tapping ou Two Hands é a técnica muito utilizada por Stanley Jordan, Steve Vai e que foi iniciada pelo guitar hero Eddie Van Halen na década de 80 no rock ' $n$ roll. Para fazer esta técnica o guitarrista toca a primeira nota com a mão da escala e posteriormente onde é informado com um (+) na pauta e um $(\mathrm{T})$ na tablatura utiliza a mão da palheta para martelar onde está indicado. Essa técnica normalmente é utilizada com fusas ou semi fusas por ser uma técnica muito rápida.

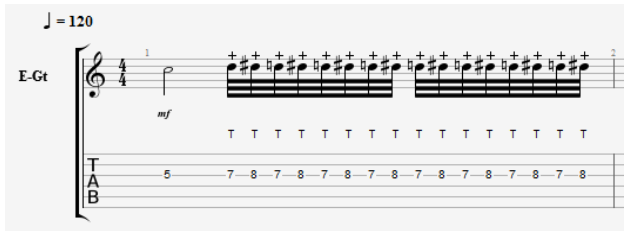

9- Palm Mute (P.M.) é uma técnica muito utilizada em rock, pois seu som percussivo faz com que se misture com o som da bateria, causando um efeito nobre. Notamos aqui que a partitura não possui nada para representar a técnica, mas na tablatura existe a notação.

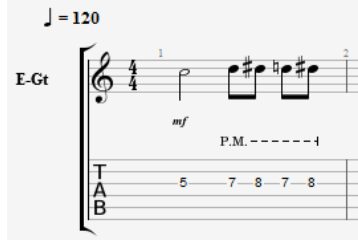

10- Let Ring é uma técnica que deixa soar a nota em questão. Aqui também não existe notação na pauta, mas sim na tablatura.

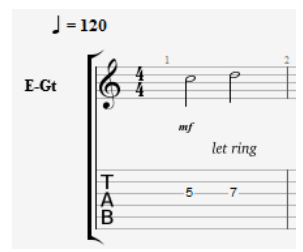

\section{Outras Situações}

Existem outras situações em que a tablatura vem beneficiar a leitura da partitura. Temos o caso em que a nota tocada deverá ser executada em determinada região do braço como disse anteriormente e se ela for utilizada com uma técnica que não há a como escrever na pauta, como fazer? Neste caso não há a possibilidade de realizar a técnica, pois se existisse somente a pauta não haveria como escrever essa determinada técnica. Vamos ao exemplo:

Uma simples escala com palhetada alternada. Na pauta não existe palhetada, pois a partitura quando confeccionada não existia a guitarra elétrica, consequentemente não existe notação para isso.

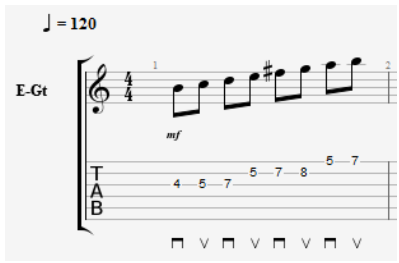

Outra situação é a seguinte, utilizando algumas técnicas notamos que a pauta fica "sem ação" perante a tablatura. Note que o arpejo descendente existe nas duas formas chegando à nota mi, logo após um Bend de um tom que aparece a notação na tablatura, note que na pauta não há notação, novamente um Palm Mute em sol, mas note que a nota que aparece na pauta poderia ser lida para tocar na $3^{\circ}$ casa na primeira corda, mas veja que na tablatura é escrito para fazer na $12^{\mathrm{a}}$ casa na terceira corda e em seguida acontece um Let Ring e termina com um Tapping na $17^{\mathrm{a}}$ casa que pela pauta seria complicado de saber onde realmente deveria ser executada.

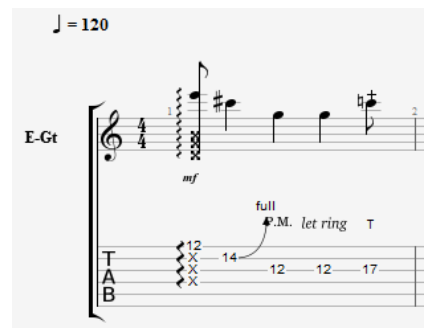


Como explicar pela pauta a utilização do uso da alavanca, aqui mostro um exemplo que utiliza uma "alavancada" de 11/2 tom e em seguida desce a mais de 5 tons terminando com um vibrato.

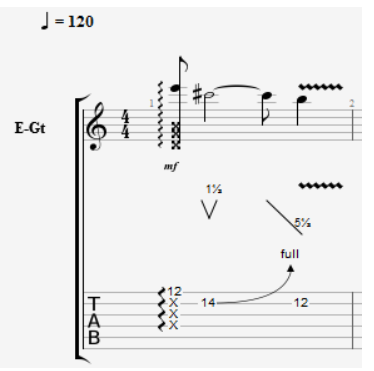

\section{CONCLUSÃO}

Apesar de algumas técnicas serem escritas tanto na partitura quanto na tablatura é notório que a tablatura auxilia a leitura e a escrita para o bom desempenho musical. As duas escritas trabalhando em conjunto pode dar ao leitor ou escritor a possibilidade de passar exatamente o que deseja utilizando as técnicas de guitarra sem nenhum problema.

Para o desenvolvimento musical da guitarra elétrica, a associação Pauta - Tablatura vem demonstrando que sua utilização para a guitarra elétrica facilita e beneficia os músicos em várias questões.

A facilidade de leitura é um quesito importante para o desempenho do guitarrista, porque quanto mais rápido o aprendizado, mais rápido o aluno poderá se aperfeiçoar musicalmente. Não quero dizer que o aluno não tenha que aprender a notação musical pela pauta, ele tem sim que ler a pauta tanto como ler a tablatura.

É notório que a tablatura possuindo as nomenclaturas essenciais para as técnicas de guitarra elétrica faz com que sua utilização em revistas, livros e material didático possa ser amplamente divulgado e utilizado para o bom desempenho musical.

\section{REFERÊNCIAS}

HORA, V.M. A Importância da Guitarra Elétrica no Rock para a Educação Musical a partir de sua
Consolidação Acadêmica e Exposição na Mídia. Monografia (graduação), UFRJ, 28 p., 2007.

NEELY, B.; SCHROEDL, J. Chords \& Scales for Guitar. Milwaukee: Hal Leonard Corporation, 1997.

HENDERSON, David. A vida de Jimi Hendrix. Dá licença que eu vou beijar o céu. Rio de janeiro: Espaço e Tempo, 1993. 